\title{
Evolution of hard Fe-C electrodeposits with temperature
}

\author{
Nielsen, Jacob Obitsø; Pantleon, Karen
}

Published in:

Surface Engineering

Link to article, DOI:

10.1080/02670844.2019.1675305

Publication date:

2020

Document Version

Peer reviewed version

Link back to DTU Orbit

Citation (APA):

Nielsen, J. O., \& Pantleon, K. (2020). Evolution of hard Fe-C electrodeposits with temperature. Surface Engineering, 36(9), 960-965 . https://doi.org/10.1080/02670844.2019.1675305

\section{General rights}

Copyright and moral rights for the publications made accessible in the public portal are retained by the authors and/or other copyright owners and it is a condition of accessing publications that users recognise and abide by the legal requirements associated with these rights.

- Users may download and print one copy of any publication from the public portal for the purpose of private study or research.

- You may not further distribute the material or use it for any profit-making activity or commercial gain

- You may freely distribute the URL identifying the publication in the public portal

If you believe that this document breaches copyright please contact us providing details, and we will remove access to the work immediately and investigate your claim 


\title{
Evolution of hard Fe-C electrodeposits with temperature
}

Jacob Obitsø Nielsen*, Karen Pantleon

Technical University of Denmark, Department of Mechanical Engineering, Produktionstorvet, building 425, DK - 2800 Kongens Lyngby, Denmark

*Corresponding author: jacobon@mek.dtu.dk

\begin{abstract}
The high microhardness of electrodeposited Fe-C coatings with around $800 \mathrm{HV}$ after electrodeposition increased to about $1300 \mathrm{HV}$ by dedicated annealing, reflecting a huge potential for surface engineering. The coatings remain nanocrystalline during annealing, but co-deposited carbon and oxygen result in temperature induced phase transformations. Energy-dispersive synchrotron diffraction revealed that carbides and oxides form during annealing of the asdeposited coating, which consisted mainly of carbon-free ferrite. The understanding of occurring precipitations was supplemented and verified by in-situ thermal analysis, which revealed the temperatures of thermal events related to decomposition reactions, the evolution of gasses and associated mass changes during annealing.
\end{abstract}

Keywords: X-ray diffraction, Coating, Nanocrystalline, Annealing, Phase transformations, Electrodeposition. 


\section{Introduction}

Despite the enormous attention on iron-carbon alloys for a wide range of surface engineering applications, their synthesis by electrodeposition is still less in focus compared to, for example, thermo-chemical treatments. The addition of organic species, like carboxylic acids, to traditional iron-sulphate electrolytes provides the carbon source that enables the co-deposition of carbon together with iron, resulting in Fe-C coatings with thicknesses of up to several hundreds of micrometers. The structure and functional groups of various carboxylic additives influence the amount of co-deposited carbon and, to some extent, the morphology and associated properties of the Fe-C coatings [1-6]. High microhardness values (up to around $800 \mathrm{HV}$ ) [7] are consistently reported for electrodeposited $\mathrm{Fe}-\mathrm{C}$ coatings and, hence, the coatings provide a favourable alternative to hardened steels. The more versatile process of electrodeposited $\mathrm{Fe}-\mathrm{C}$ compared to (surface) hardening of steels allows producing hard and wear-resistant coatings on a variety of different substrates, performing site-specific deposition for repairing surfaces and tailoring the internal structure of the coatings according to the deposition process parameters, and it offers a huge potential for surface engineering by post-deposition treatment. In this respect, not only the nature of as-deposited coatings, but also their thermal stability including the evolution of the microstructure and occurring phase transformations are of interest.

In our recent work [6], we have shown that as-deposited Fe-C coatings consist of nanocrystalline grains and form strong $<311>$ fibre textures independent of the coating thickness. Despite the high concentration of carbon, which amounts to $0.88 \mathrm{wt}-\%$ in the as-deposited coatings, the majority of grains correspond to ferrite with bcc crystal structure and the strain-free lattice spacing as measured by X-ray diffraction (XRD) does not indicate any (supersaturated) solid solution of carbon [6]. The presence of a minor second phase has been suggested by XRD, but 
thorough identification of that phase is hindered by the limited number and weak intensity of corresponding peaks: only a single peak, in addition to ferrite, can be detected clearly $[5,6,8,9]$. This second phase may originate from the co-deposited carbon (e.g. $\mathrm{Fe}_{2} \mathrm{C}$ carbides $[6,8]$ ), but it also may be related to further elements like oxygen and hydrogen, which indeed are detected although not quantifiable in as-deposited coatings, and/or a combination of all present elements being iron, carbon, oxygen and hydrogen. To reveal the role of these elements, which reproducibly are detected in electrodeposited Fe-C coatings [2,6-8,10,11], the present work investigates the evolution of as-deposited coatings during annealing and reveals corresponding phase transformations by means of complementary thermal analysis and diffraction analysis, further supplemented with transmission electron microscopy.

\section{Material and methods}

\section{Electrodeposition}

The same Fe-C coatings, which previously have been studied in their as-deposited state [6], have been used for the present annealing study. Deposition from an iron-sulphate electrolyte with citric acid as an additive $\left(0.143 \mathrm{~mol} / \mathrm{dm}^{3} \mathrm{FeSO}_{4} \cdot 7 \mathrm{H}_{2} \mathrm{O}, 6.2 \times 10^{-3} \mathrm{~mol} / \mathrm{dm}^{3} \mathrm{C}_{6} \mathrm{H}_{8} \mathrm{O}_{7} \cdot \mathrm{H}_{2} \mathrm{O}\right)$ occurred with a constant current density of $3.0 \mathrm{~A} / \mathrm{dm}^{2}$ (for details, see [6]). As cathode, thin brass strips and lead-tape were attached on a steel plate such that deposition occurred simultaneously on lead and brass, thus, under exact same conditions. The substrate material does not play a role for the present study, because the long deposition with $15 \mathrm{~h}$ resulted in a thick coating of 360 $\mu \mathrm{m}$. Low adhesion of the coating on lead allowed easy detaching from the substrate to obtain stand-alone coatings for in-situ thermal analysis, while coatings on brass were used for ex-situ annealing. 


\section{Characterization methods}

Simultaneous thermogravimetry (TGA) and differential thermal analysis (DTA) were performed in a Netzsch STA 449F3 coupled with a Netzsch QMS 403 Aëolos quadrupole mass spectrometer (MS). The setup enables the detection and identification of evolved gases in time correlation with enthalpy and mass changes. For each measurement, a piece of substrate-free coating material, detached from the lead-tape and weighing 250-260 mg, was placed in an alumina crucible. Isothermal annealing experiments were carried out at temperatures of 200, 250 and $300{ }^{\circ} \mathrm{C}$, respectively, with a holding time of $24 \mathrm{~h}$ at each temperature. Each of the isothermally treated samples, was subsequently further subjected to two cycles of isochronal annealing from $40{ }^{\circ} \mathrm{C}$ to $800{ }^{\circ} \mathrm{C}$, using a heating rate of $2 \mathrm{~K} \mathrm{~min}^{-1}$ and a cooling rate of $40 \mathrm{~K} \mathrm{~min}^{-}$ 1, whereby the second isochronal annealing was used to correct for the instrumental background

of the first isochronal annealing. As a reference, an as-deposited coating was subjected to the two isochronal heating cycles. Annealing was carried out in an inert atmosphere of argon gas (99.999 mol-\% purity).

Identical counterparts of the coating on brass substrates were used for furnace annealing in a lower temperature range up to a maximum of $300{ }^{\circ} \mathrm{C}$. Such furnace annealing was carried out for $24 \mathrm{~h}$ at isothermal temperatures of 200,250 and $300^{\circ} \mathrm{C}$, respectively, in an inert argon (99.999 mol-\% purity). Qualitative phase analysis was carried out for each sample at the synchrotron diffraction facility BESSY II using energy-dispersive diffraction (EDD) at the EDDI beamline [12]. EDD spectra were recorded for $600 \mathrm{~s}$ applying a symmetric diffraction geometry with a constant scattering angle $2 \theta=14^{\circ}$, corresponding to a maximum information depth of about 100 $\mu \mathrm{m}$. For phase analysis, the diffraction lines were fitted with pseudo-Voigt functions. A gold reference standard was used for calibration of the energy offset. 
Fe-C coatings in both the as-deposited state and after annealing at $300{ }^{\circ} \mathrm{C}$ for $24 \mathrm{~h}$ have been prepared for transmission electron microscopy (TEM) analysis. Applying the focused-ion beam lift-out technique in a dual beam FEI Helios EBS3 microscope, samples were prepared in plan view at about half of the total thickness of the $360 \mu \mathrm{m}$ thick Fe-C coatings. TEM investigation applying bright field imaging (BF) and selected area electron diffraction (SAED) was carried out with an accelerating voltage of $300 \mathrm{kV}$ using a Joel $3000 \mathrm{~F}$ microscope.

Microhardness measurements were performed on metallographically prepared cross sections of the exact same Fe-C coatings of the present diffraction analysis. A Future Tech Inc. FM700 microhardness tester with Vickers geometry was applied with a load of $25 \mathrm{~g}$ and represented data average over five measurements per sample.

\section{Results and discussion}

The EDD spectra of the as-deposited and ex-situ annealed Fe-C coatings are shown in Figure 1. Consistent with results from conventional laboratory XRD [6], the as-deposited coating mainly consists of $\alpha$-iron and a second phase is indicated by one additional peak at $21.51 \mathrm{keV}$ (Figure 1(a)) corresponding to a d-spacing of $0.2365 \mathrm{~nm}$, which confirms our previous measurements. Although this single peak of an additional phase is reproducibly measured and also reported in literature $[5,6,8]$, the corresponding phase analysis has not yet been unambiguously, as mentioned above (therefore, here, it is referred to 'nameless peak'), and it is of interest to follow the evolution of this peak/phase by annealing. Figure 1(b) shows that the nameless peak remains unchanged even after annealing of $24 \mathrm{~h}$ at $250^{\circ} \mathrm{C}$, and its position, intensity and width are identical to the ones for the as-deposited coating. In the same temperature range, where the nameless peak still is unaffected, $\mathrm{Fe}_{3} \mathrm{O}_{4}$ (magnetite) develops (cf. Figure 1(b)). As the applied inert gas excludes oxidation from the furnace and no oxide layer has been found on the surface, 
the formation of magnetite has occurred throughout the coating. This confirms that oxygen has been present already in the as-deposited coating, which agrees with the detection of oxygen by chemical analysis with glow discharge optical emission spectroscopy and electron energy loss spectroscopy, although quantification of the as-deposited oxygen concentration has not been possible yet [6]. While the oxide is detected already at $200^{\circ} \mathrm{C}$, still there is no clear indication for a carbon-containing phase (except from the vague relation to the nameless peak) and first at $250{ }^{\circ} \mathrm{C}$, carbides of $\mathrm{Fe}_{3} \mathrm{C}$ (cementite) are clearly detected (cf. Figure 1(b)). With further increasing temperature to $300{ }^{\circ} \mathrm{C}$, both magnetite and cementite further evolve towards higher intensities, while the nameless peak simultaneously reduces in intensity. Although of low intensity, the nameless peak is still present after annealing at $300{ }^{\circ} \mathrm{C}$, as indicated by the observed asymmetry of the higher intense peak of $\mathrm{Fe}_{3} \mathrm{C}$ at about the same position (cf. Figure 1(b)). The decrease in intensity of the nameless peak, simultaneously with a significant increase in the intensities of all peaks related to both $\mathrm{Fe}_{3} \mathrm{C}$ and $\mathrm{Fe}_{3} \mathrm{O}_{4}$ suggest that the phase related to the nameless peak contains carbon and oxygen.

\section{[Figure $1 \mathrm{a} \& 1 \mathrm{~b}]$}

To verify the phase transformations as revealed by diffraction analysis and to understand the nature and evolution of the nameless peak/phase of the as-deposited coatings, thermal analysis during isochronal annealing of both an as-deposited coating and previously isothermally annealed coatings for $24 \mathrm{~h}$ at 200,250 and $300^{\circ} \mathrm{C}$ has been carried out by simultaneous DTA, TGA and MS analysis. Figure 2 shows, on the example of occurring weight changes, the thermal desorption of $\mathrm{H}_{2} \mathrm{O}$ (related to desorption of hydrogen), and the enthalpy changes, that the as- 
deposited $\mathrm{Fe}-\mathrm{C}$ coating undergoes four thermal events at distinct temperatures during isochronal annealing.

The first event at around $115^{\circ} \mathrm{C}$ is defined by an exothermic peak (cf. Figure 2), a desorption of hydrogen and corresponding mass loss, which is related to dehydrogenation of adsorb hydrogen originating from the electrolysis of water during the deposition process. The entrapment of hydrogen into the growing coating is typical for electrodeposition and manifests in reduced current efficiency, which indeed for the present samples amounted to $60.5 \%$. This atomic or molecular hydrogen can easily evaporate and, accordingly, this reaction only is measured for the as-deposited coating and not for the already annealed samples. The second event at around 275 ${ }^{\circ} \mathrm{C}$ (cf. Figure 2) is visible for the as-deposited sample and for samples annealed at $200{ }^{\circ} \mathrm{C}$ and $250{ }^{\circ} \mathrm{C}$, and relates to a thermal decomposition, which is characterized by a further release of hydrogen and a mass loss. The observation that the hydrogen release in the second event is lower for the $250{ }^{\circ} \mathrm{C}$ annealed sample compared to $200{ }^{\circ} \mathrm{C}$ and not occurring after higher annealing temperature of $300{ }^{\circ} \mathrm{C}$, indicates that the corresponding phase still is intact after isothermal annealing at $200{ }^{\circ} \mathrm{C}$, partly decomposed after $250{ }^{\circ} \mathrm{C}$ annealing and fully decomposed at $300{ }^{\circ} \mathrm{C}$. The precipitation of $\mathrm{Fe}_{3} \mathrm{C}$ for samples annealed at $250{ }^{\circ} \mathrm{C}$ and $300{ }^{\circ} \mathrm{C}$, respectively, as measured by EDD (cf. Figure 1(b)), further reveals that carbon originally is bound to the phase decomposing at the second event. As the nameless peak/phase still is recorded by EDD after isothermal annealing at $250{ }^{\circ} \mathrm{C}$ without any changes compared to its as-deposited state, the occurring thermal decomposition in the second thermal event does not seem to relate to that phase. The third event at around $360{ }^{\circ} \mathrm{C}$ (cf. Figure 2) is identified as a thermal decomposition by an exothermic reaction, a further release of hydrogen and a mass loss. This thermal decomposition at $360{ }^{\circ} \mathrm{C}$ is measured for all samples, but is much less prominent for the $300{ }^{\circ} \mathrm{C}$ 
annealed sample, where only the mass loss and a release of hydrogen indicate the reaction. This could be associated with the nameless peak/phase measured by EDD, since the intensity of the peak has decreased significantly after isothermal annealing at $300{ }^{\circ} \mathrm{C}$ (cf. Figure 1b). Such a correlation would reject the hypothesis that the nameless peak originates from $\mathrm{Fe}_{2} \mathrm{C}$ (either $\varepsilon$ - or $\eta$-phase, as previously suggested $[6,8])$, since its transformation into $\mathrm{Fe}_{3} \mathrm{C}$ cannot be associated with a mass loss or release of hydrogen [13]. The temperature of $360{ }^{\circ} \mathrm{C}$ is also higher than the reported transformation temperature of $\varepsilon / \eta-\mathrm{Fe}_{2} \mathrm{C}$ to $\mathrm{Fe}_{3} \mathrm{C}$ [13], but is in good agreement with a former study of the decomposition of ferrihydrite [14]. The suggestion of the nameless phase being a hydroxide would be supported by the observed release of hydrogen during annealing and the measured d-spacing of the nameless peak with $d=0.2365 \mathrm{~nm}(\mathrm{E}=21.51 \mathrm{keV}$, Figure 1) would correspond to $\mathrm{d}_{004}=0.234 \mathrm{~nm}$ of $\mathrm{FeOOH}$ (ferrihydrite), although this is the only observable peak of that phase, as mentioned above. However, ferrihydrite, as the possible second phase in the as-deposited Fe-C coating, only consists of iron, oxygen and hydrogen, but not carbon. Accordingly, its decomposition would not account for the release of carbon required for the growth of $\mathrm{Fe}_{3} \mathrm{C}$. Instead, the carbon required for the growth of $\mathrm{Fe}_{3} \mathrm{C}$ may originate from the phase decomposing in the second event. Accordingly, the $300{ }^{\circ} \mathrm{C}$ annealed sample has already underwent that decomposition fully, which has supplied carbon for the growth of $\mathrm{Fe}_{3} \mathrm{C}$, and, simultaneously, ferrihydrite related to the third event has partly decomposed and released oxygen for the growth of $\mathrm{Fe}_{3} \mathrm{O}_{4}$. The fourth event at around $505{ }^{\circ} \mathrm{C}$ (cf. Figure 2) is revealed as a small exothermic reaction for the as-deposited sample only. This event is not associated with any mass loss or release of hydrogen. The observed temperature of that event does not relate to any expected transformation of $\alpha-\mathrm{Fe}, \mathrm{Fe}_{3} \mathrm{C}$ or $\mathrm{Fe}_{3} \mathrm{O}_{4}$ [15-17], but a second exothermic reaction has 
been reported for ferrihydrite [14], which explains that only the as-deposited coating further evolves at that temperature.

\section{[Figure2]}

Supplementing the results from diffraction analysis and thermal analysis regarding the presence and thermal evolution of phases in the Fe-C coating, TEM reveals that the as-deposited coating is nanocrystalline. The applied plan-view investigations show average grain sizes of $15-40 \mathrm{~nm}$ for the as-deposited coating, as shown in Figure 3(a). These grains result in fine rings in the SAED pattern shown in Figure 3(b), which correspond to the ferrite phase, in agreement to the results from synchrotron diffraction for the as-deposited coating (cf. Figure 1). In addition to ferrite, also a uniformly occupied diffraction ring indicating magnetite $\mathrm{Fe}_{3} \mathrm{O}_{4}$ is detected, which has not been revealed by synchrotron diffraction. Based on the knowledge of co-deposited oxygen [6], the oxide may have formed during electrodeposition but with too low volume fraction for being detected by synchrotron diffraction covering a larger sample volume, but it also may indicate the challenges of preventing oxidation of ferrite during preparation, handling or storage of the thin TEM lamella. Interestingly, there are no diffraction spots matching the d-spacing of the nameless peak or other spots related to the nameless phase, which is known to be present in the asdeposited coating based on EDD (cf. Figure 1); however, both diffraction methods relate to a different measurement direction in the coating.

\section{[Figure3]}

After ex-situ annealing at $300^{\circ} \mathrm{C}$ for $24 \mathrm{~h}$ (same sample as used for EDD), the ferrite grains are still nanocrystalline and Figure 4(a) in plane-view reveals an average size of the grains in the order of 30-50 nm. The corresponding SAED pattern (Figure 4(b)) for this annealed Fe-C 
coating clearly reveals that cementite $\mathrm{Fe}_{3} \mathrm{C}$ and magnetite $\mathrm{Fe}_{3} \mathrm{O}_{4}$ have formed during annealing. This is consistent with synchrotron diffraction results of the annealed coatings, which reveal magnetite formation already after annealing at $200{ }^{\circ} \mathrm{C}$ with nanocrystalline dimensions as indicated by the fairly broad peaks (cf. Figure 1).

\section{[Figure4]}

Microhardness measurements on cross sections of the nanocrystalline $\mathrm{Fe}-\mathrm{C}$ coatings revealed high microhardness of $784 \pm 12 \mathrm{HV} 0.025$ for the as-deposited coating. The occurring phase transformations during annealing suggest a further hardness increase. Indeed, isothermal annealing at 200,250 and $300{ }^{\circ} \mathrm{C}$ increased the microhardness of the $\mathrm{Fe}-\mathrm{C}$ coatings to $883 \pm 28$ HV0.025 $\left(200{ }^{\circ} \mathrm{C}\right), 957 \pm 17 \mathrm{HV} 0.025\left(250^{\circ} \mathrm{C}\right)$ and $1286 \pm 27 \mathrm{HV} 0.025\left(300^{\circ} \mathrm{C}\right)$. The absence of significant grain growth of ferrite and the evolving oxide and carbide phases being of small dimensions and distributed within the whole coating according to the origin of carbon and oxygen from the electrodeposition process, essentially contribute to the observed increase of the hardness by annealing.

\section{Conclusion}

The applied complementary methods of microscopy, diffraction analysis and thermal analysis strongly support the understanding of both the as-deposited Fe-C coatings as well as their evolution during annealing. The results reveal the important role of carbon, oxygen and hydrogen, which previously have been detected in as-deposited coatings, but are challenging to be quantified by chemical analysis. The origin of carbon, oxygen and hydrogen strongly relates to the deposition process with citric acid as an additive and complexing agent in the iron sulphate electrolyte. Although mainly the co-deposition of carbon has been intended for the electrodeposited $\mathrm{Fe}-\mathrm{C}$ coatings, the formation of phases during deposition and the occurring phase transformations during annealing are clearly governed by more than just carbon and iron. 
The synergetic effect of all these elements together with the nanocrystalline nature of the coatings explain the excellent mechanical properties of the electrodeposited Fe-C coatings and make them a favourable candidate for wear resistant surfaces.

\section{Acknowledgements}

The authors are grateful to Christoph Genzel, Manuela Klaus and Daniel Apel (HZB, Germany) for experimental support at the beamline EDDI of BESSY II. Flemming Bjerg Grumsen (DTU, Denmark) is acknowledged for TEM analysis and Thomas Lundin Christiansen (DTU, Denmark) is acknowledged for discussions on thermal analysis. Financial support by OCAS NV, ArcelorMittal Global R\&D Gent (Belgium), a. h. nichro Haardchrom (Denmark) and Fast Track

- Societal Partnership (Denmark), funded by the Innovation Fund Denmark (IFD), is kindly acknowledged.

\section{Disclosure statement}

No potential conflict of interest was reported by the authors.

\section{References}

[1] Fujiwara Y, Izaki M, Enomoto H, et al. Effects of Hydroxycarboxylic Acids on the Electrodeposition of Fe-C Alloys. Denki Kagaku. 1993;7:840-842.

[2] Fujiwara Y, Nagayama T, Nakae A, et al. Electrodeposition of Fe-C Alloys from Baths Containing Dicarboxylic Acids with a Linear Alkyl Chain. J. Electrochem. Soc. 1996;143:2584-2590.

[3] Fujiwara Y, Izaki M, Enomoto H, et al. Optimization of bath composition for hard $\mathrm{Fe}-\mathrm{C}$ 
alloy plating. J. Appl. Electrochem. 1998;28:855-862.

[4] Panayotova M. Deposition of Fe-C alloy on structural steel and cast iron for repair of worn machine parts. Surf. Coat. Technol. 2000;124:266-271.

[5] Müller T, Grimwood J, Bachmaier A, et al. Electrodeposition of Fe-C alloys from citrate baths: Structure, mechanical properties, and thermal stability. Metals. 2018;8:1-13.

[6] Nielsen JO, Møller P, Pantleon K. Electrodeposition of iron with co-deposition of carbon - on the nature of nanocrystalline Fe-C coatings. Metall. Mater. Trans. A. 2019;50A:3785-3793

[7] Izaki M, Omi T. Structural characterization of martensitic iron-carbon alloy films electrodeposited from an iron(11) sulfate solution. Metall. Mater. Trans. A. 1996;27A:483486.

[8] Haseeb ASMA, Hayashi Y, Masuda M, et al. On the nature of the electrochemically synthesized hard Fe-0.96 mass pct C alloy film. Metall. Mater. Trans. B. 2002;33B:921927.

[9] Miyamoto N, Sakamoto S, Tamura H, et al. Effect of Carbon Content on Structural and Mechanical Properties of Fe-Co-C Alloy Electrodeposited from Aqueous Solutions. J. Electrochem. Soc. 2005;152:C488-C492.

[10] Haseeb ASMA, Nishida T, Masuda M, et al. Mössbauer investigation on electrodeposited Fe-C and Fe-Ni-C alloys. Scr. Mater. 2001;44:519-523. 
[11] Haseeb ASMA, Arita M, Hayashi Y. Thermal decomposition study of electrodeposited Fe-C and Fe-Ni-C alloys by differential scanning calorimetry. J. Mater. Sci. 2001;6:47394743.

[12] Genzel C, Denks I. A, Gibmeier J, et al. The materials science synchrotron beamline EDDI for energy-dispersive diffraction analysis. Nucl. Instruments Methods Phys. Res. A. 2007;578:23-33.

[13] Cheng L, Brakman CM, Korevaar BM, et al. The Tempering of Iron-Carbon Martensite; Dilatometric and Calorimetric Analysis. Metall. Trans. A. 1988;19A:2415-2426.

[14] Campbell AS, Schwertmann U, Campbell PA. Formation of cubic phases on ferrihydrite heating. Clay Miner. 1997;32:615-622.

[15] Chipman J. Thermodynamics and Phase Diagram of the Fe-C System. Metall. Trans. 1972;3:55-64.

[16] Yakel HL. Crystal structures of stable and metastable iron-containing carbides. Int. Met. Rev. 1985;30:17-40.

[17] Wriedt HA. The Fe-O (Iron-Oxygen) System. J. Phase Equilibria. 1991;12:170-200. 


\section{Figures}
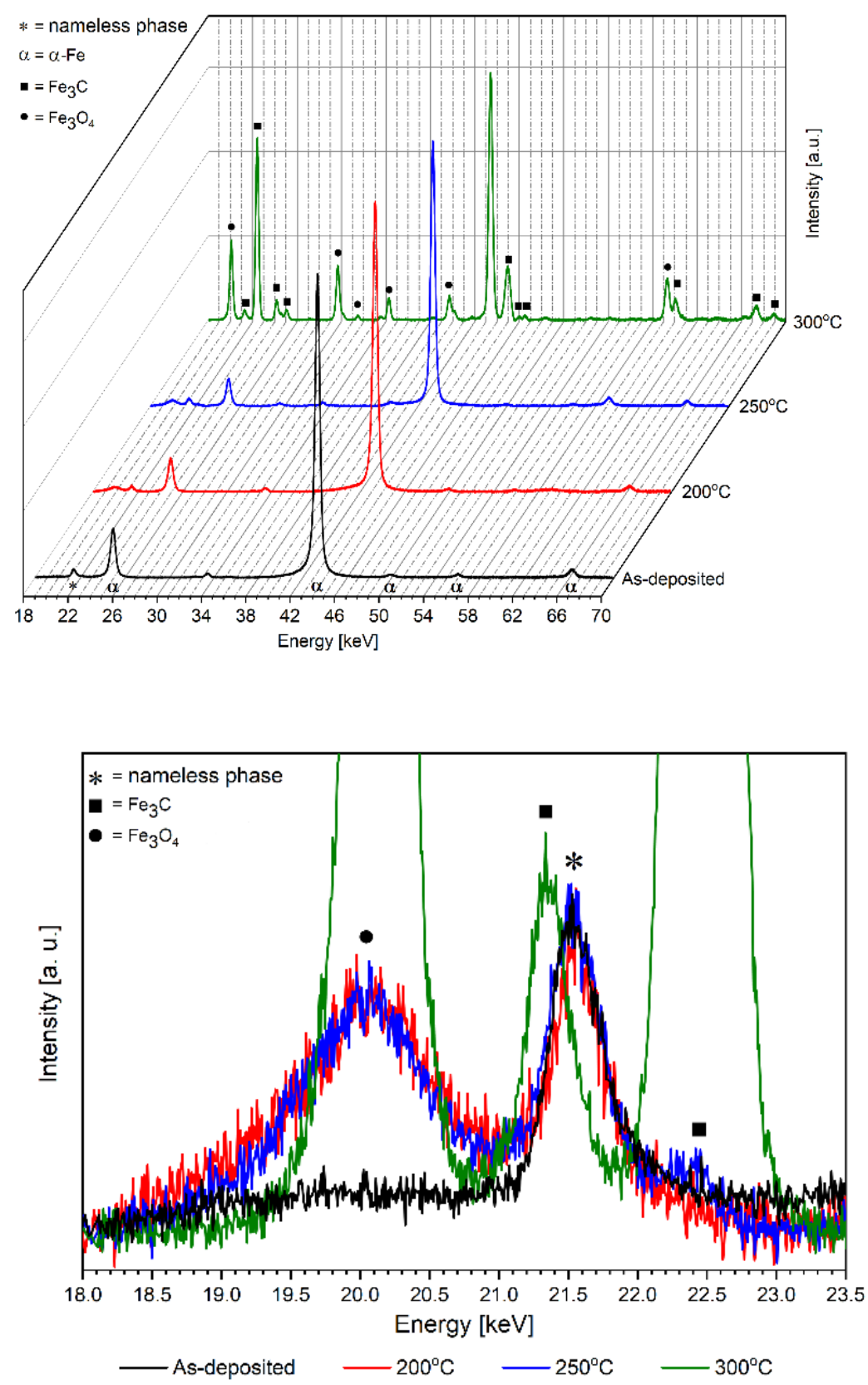

Figure 1: Energy-dispersive diffraction spectra of Fe-C coatings: as-deposited (black) and after isothermal annealing for 24 hours at $200{ }^{\circ} \mathrm{C}$ (red), $250{ }^{\circ} \mathrm{C}$ (blue) and $300{ }^{\circ} \mathrm{C}$ (green). (a) Overview. Note: The peak at $33.61 \mathrm{keV}$ corresponds to an escape peak from $\alpha-211 . \mathrm{b}$ ) Magnified region to indicate phase transformations, see details in the text. 


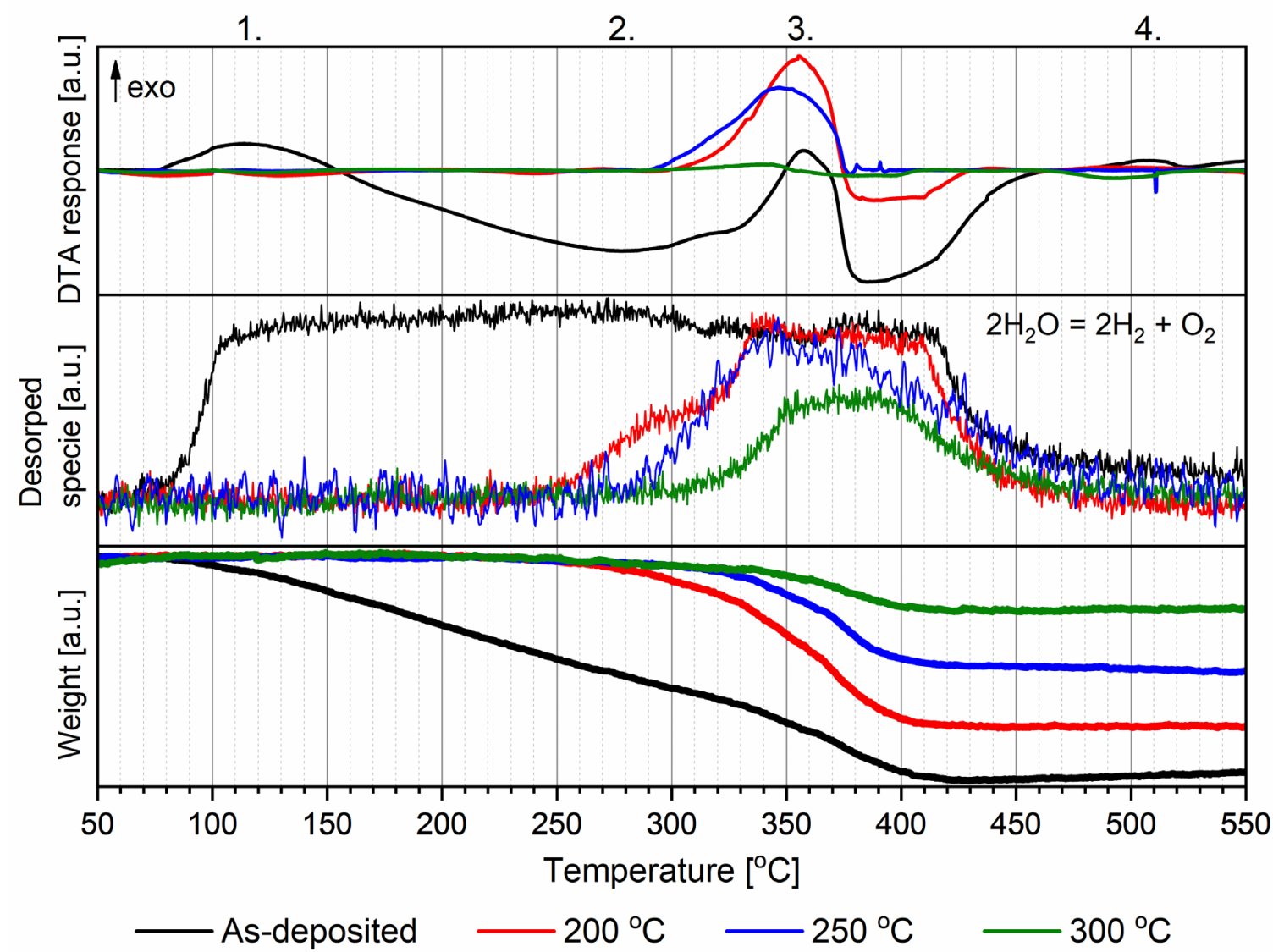

Figure 2: Thermal analysis by DTA, MS and TGA for Fe-C coatings: as-deposited (black) and after isothermal annealing for 24 hours at $200{ }^{\circ} \mathrm{C}$ (red), $250{ }^{\circ} \mathrm{C}$ (blue) and $300{ }^{\circ} \mathrm{C}$ (green). The signal from $\mathrm{H}_{2} \mathrm{O}^{+}$is used as a marker for the desorption of hydrogen, since hydrogen released from the sample will reacts with the oxygen impurity in the argon $\left(2 \mathrm{H}_{2}+\mathrm{O}_{2} \rightarrow 2 \mathrm{H}_{2} \mathrm{O}\right)$ and produces an increased signal of $\mathrm{H}_{2} \mathrm{O}$. The numbers 1 to 4 corresponds to the thermal events described in the text. 

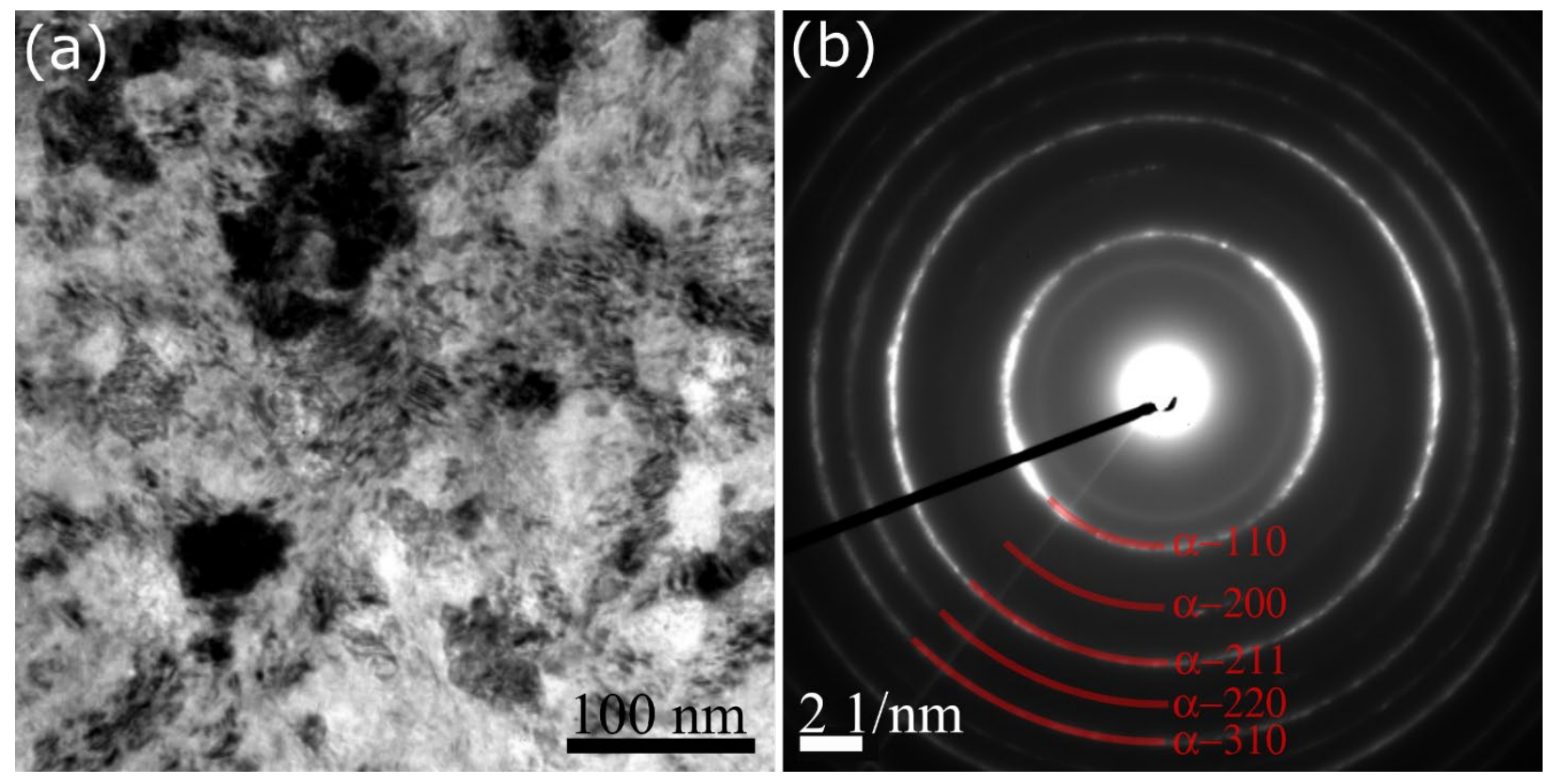

Figure 3: TEM micrograph (a) and corresponding selected area electron diffraction pattern (b) of the as-deposited Fe-C coating in plan-view.
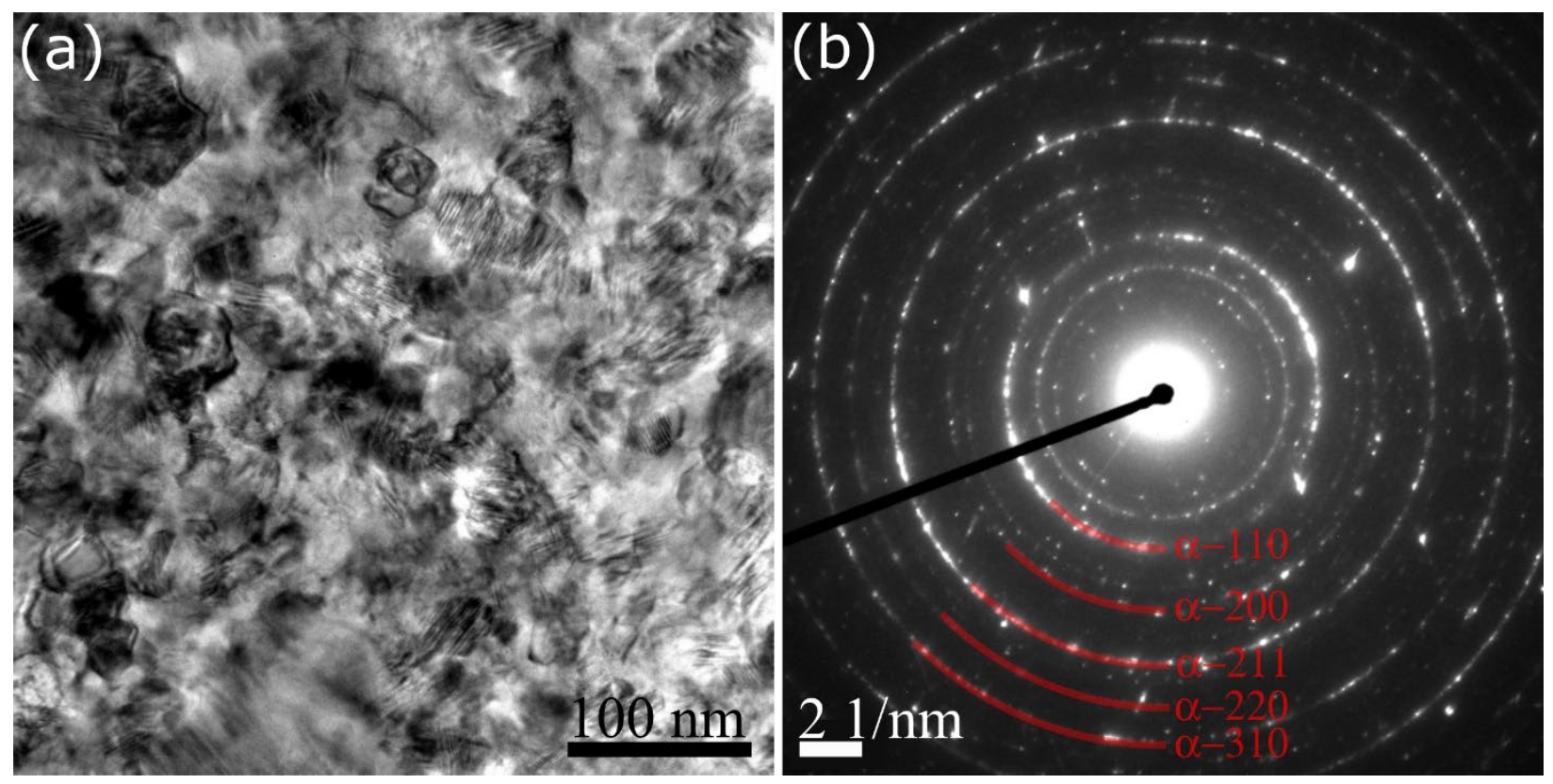

Figure 4: TEM micrograph in plan view (a) and corresponding selected area electron diffraction pattern (b) of the Fe-C coating ex-situ annealed at $300{ }^{\circ} \mathrm{C}$ for 24 hours. 